\title{
Microorganisms associated to tomato seedlings growing in saline culture act as osmoprotectant
}

\author{
Daniel Cortés-Jiménez ${ }^{2}$, Abril Gómez-Guzmán ${ }^{1,2}$, Gabriel Iturriaga ${ }^{3}$, Ramón Suárez ${ }^{3}$, \\ Gisela Montero Alpírez ${ }^{2}$, Froylán M.E. Escalante ${ }^{1}$ \\ ${ }^{1}$ Laboratory of Microbial Processes, Department of Chemistry, Autonomous University of Guadalajara, \\ Zapopan, Jalisco, Mexico. \\ ${ }^{2}$ Department of Engineering, Autonomous University of Baja California, Mexicali, Baja California, \\ Mexico. \\ ${ }^{3}$ Centro de Investigación en Biotecnología, Universidad Autónoma del Estado de Morelos, Cuernavaca, \\ Morelos, Mexico.
}

Submitted: Junho 10, 2013; Approved: September 9, 2013.

\begin{abstract}
Less than $0.5 \%$ of total water in the world is available for human consumption and agriculture. The major part of the world's water is saline and salinity in soils interferes in germination of seeds and the posterior development of the plant. In order to increase the osmotolerance of tomato, seedlings were associated with Azospirillum brasilense Cd, Azospirillum brasilense Cd transformed bacteria with a plasmid harboring a trehalose biosynthesis gene-fusion or Chlorella vulgaris. Two plant culture media: Hydroponic and Murashige and Skoog were tested. In the first set of studies seedlings were associated to single free cells meanwhile in a second set single and combined free cells were studied. A positive interaction between transformed Azospirillum and Chlorella vulagris and tomato plants was observed. Seedlings showed a salt concentration tolerance, as sodium chloride, up to $200 \mathrm{mM}$. According to our results, the association of plants with $A$. brasilense Cd-BIF and C. vulgaris is a viable approach to increase their salt tolerance and biomass, as consequence the possible use of sea water to irrigate horticultural plants.
\end{abstract}

Key words: hydroponic culture, microbial association, salt tolerance, Trehalose.

\section{Introduction}

The negative impact of salinity on plant growth in irrigated and non-irrigated areas of the world's arid regions is a major problem for agriculture (Nasr et al., 2011; Meloni et al., 2008; Ríos-Gómez et al., 2010; Velarde et al., 2003). Salinization is a process of soil enrichment with salts more soluble than calcium sulfate, usually chlorides and sulfates of sodium and magnesium. This causes osmotic stress and plant intoxication, thus interfering with the growth of most crops (Porta et al., 1999). Plants develop a plethora of biochemical and molecular mechanisms to cope with salt stress. These processes include compartmentalization of compatible solutes, change in photosynthetic pathway, alteration in membrane structure, induction of antioxidative enzymes and plant hormones and as a consequence plants redirect their growth when exposed to stress (El-Baky et al., 2008). It is hypothesized that such morphogenic responses are part of a general acclimation strategy that constitutes the 'flight' response of plants (Potters et al., 2007). The initial effects of increasing soil salinity are very similar to those observed when plants are exposed to drought. Reductions in leaf water potential will reduce stomatal conductance and eventually inhibit photosynthetic metabolism (Zribi et al., 2009).

Numerous studies have shown that in saline environments, adaptation to salinity during germination and early stages of seedling growth are crucial in determining the success of the establishment. Even in the late stages of development salinity may affect the distribution of plants in certain species (Tobe, 2000).

Send correspondence to F.M.E. Escalante. Laboratory of Microbial Processes, Department of Chemistry, Autonomous University of Guadalajara, Av. Patria 1201, Lomas del Valle, Zapopan, 45110 Jalisco, Mexico. E-mail: froymario@edu.uag.mx. 
Salinity tolerance and other adverse conditions in soils are currently overcome with an excess of irrigation water, thus given the increasingly shortage of fresh water at global level, it is necessary to develop strategies that include both salt-resistant crops and techniques to reduce stress injury (Bacilio et al., 2004). A major effort in research has been dedicated to organic fertilization or use of biofertilizers to increase plant development. Biofertilizers are best described as microbial communities that add, preserve and mobilize soil nutrients. Azospirillum is considered one of the most studied plant growth promoting bacteria (PGPB) given its ability to significantly increase not only plant growth development, but also the yield of numerous agricultural crops (Givaudan and Bally, 1991; Strzelczyk et al., 1994). Azospirillum brasilense promotes growth due to the accumulation and transport of indole-3acetic acid to the plant (Umali-Garcia et al., 1980; Hartmann et al., 1983) and other plant growth regulation molecules such as absicic acid (ABA) and diamine cadaverine (CAD) (Canto Martín et al., 2004; Perrig et al., 2007).

Azospirillum spp. colonizes the roots of a wide range of crops and can efficiently colonize roots submerged in growth solutions, and thus increase plant growth. The ability of Azospirillum spp. to stimulate plant growth has been widely demonstrated in experiments both field and greenhouse. Several mechanisms have been suggested to be responsible for the stimulatory effect observed in the inoculated plants in numerous studies and inoculation with Azospirillum spp.

In the last decade it has been demonstrated that Azospirillum brasilense increases the growth parameters not only of superior plants but unicellular microalgae Chlorella spp. by changing its cytology and metabolic parameters (de Bashan et al., 2004). This phenomena is also associated with the potential of Azospirillium spp. to produce plant growth regulators, because the microalga responds to the presence of Azospirillum similarly to higher plants, increasing their growth and changing its metabolism, due to the green microalgae meet the basic requirements of a higher plant (Mazur et al., 2001; Stirk et al., 2002).

Recently, it has been shown that a recombinant Azospirillum brasilsence $\mathrm{Cd}$ strain expressing the omoprotectant trehalose is able to grow in salt stress conditions (Rodríguez-Salazar et al., 2009). The aim of this study is to find out if Chlorella vulgaris, Azospirillum brasilsence $\mathrm{Cd}$ and Azospirillum brasilense Cd-BIF, could increase the salt tolerance of tomato in hydroponic cultures.

\section{Material and Methods}

\section{Microalgae and bacteria}

\section{Microalgae}

Chlorella vulgaris (UTEX 2714) was grown in axenic cultures of Basal Bold Medium (Bischoff y Holtzer, 1969 ) at 2000 lux illumination with light/dark periods of $16 / 8 \mathrm{~h}$ for 14 days prior to its use. The cell concentration was adjusted to $1 \times 10^{6}$ cells $/ \mathrm{mL}$ prior to its use as inoculant.

\section{Bacteria}

Azospirillum brasilense $\mathrm{Cd}$ was grown in nutrient broth with ampicillin at $30{ }^{\circ} \mathrm{C}$ for $72 \mathrm{~h}$ prior to its use; Azospirillum basilense Cd-BIF which enables the accumulation of trehalose in excess (Rodríguez-Salazar et al., 2009) was grown in nutrient broth supplied with ampicillin and gentamycin at $30^{\circ} \mathrm{C}$ for $72 \mathrm{~h}$ prior to its use. The viability of the strains was tested on Congo Red agar plates. The cell concentration was adjusted to $1 \times 10^{9}$ cells $/ \mathrm{mL}$ prior to its use as inoculant.

\section{In vitro hydroponic culture}

\section{Hydroponic media composition}

Hydroponic media was modified from (Jensen y Malter, 1995). Composition in $\mathrm{g} / \mathrm{L}: \mathrm{MgSO} 4.7 \mathrm{H}_{2} \mathrm{O}, 0.5$; $\mathrm{K}_{2} \mathrm{HPO}_{4}, 0.27 ; \mathrm{KNO}_{3}, 0.2 ; \mathrm{K}_{2} \mathrm{SO}_{4}, 0.1 ; \mathrm{Ca}\left(\mathrm{NO}_{3}\right)_{2}, 0.5$; EDTA, $0.25 ; 250 \mu \mathrm{L}$ of trace minerals. Trace minerals composition in $\mathrm{g} / \mathrm{L}: \mathrm{H}_{3} \mathrm{BO}_{3}, 16.6 ; \mathrm{MgCl}_{2}, 15.0 ; \mathrm{CuCl}_{2}$, $0.82 ; \mathrm{MoO}_{3}, 0.33$.

\section{Tomato seeds germination}

Seeds of Solanum lycopersicum var. cherry were germinated in sterile Petri dishes with hydroponic media for 10 days under light/dark periods of 16/8 h.

\section{Plant growth and development}

Tomato plants where placed axenically in plastic conical tubes in groups of five under different sodium chloride concentrations: 0, 50, 100, 150, 200 y $250 \mathrm{mM}$ using hydroponic medium (Jensen y Malter, 1995) or Murashige and Skoog (MS) medium (Murashige y Skoog, 1962) as base. Each group of treatments was supplied with one of the following free cells cultures: AW, AB, CV, AWCV, ABCV, including a control treatment without microorganisms; note: combined microbial treatments were tested only in hydroponic culture in a second set of experiments. Tomato plants were placed in $13.5 \mathrm{~mL}$ of the corresponding media and $1.5 \mathrm{~mL}$ of the corresponding microbial culture (Table 1). Plant growth and development was monitored after 10,20 and 30 days of culture; every period stem and root length were measured.

\section{Experimental design and statistical analysis}

In order to compare the effect of media composition, time of culture and salt concentration in stem and root elongation, a multifactorial design was used. Data was analyzed using the ANOVA and Least Significant Difference (LSD) analysis at level 0.05 of confidence.

\section{Results}

Two sets of experiments were planned. In a first group, two mediums (Hydroponic and Murashige and Skoog), three periods of time (10, 20 and 30 days), six $\mathrm{NaCl}$ concentrations ( 0 to $250 \mathrm{mM}$ ) and three single cells $A$. brasilense $\mathrm{Cd}$ (AW), A. brasilense Cd-BIF (AB) and $C$. 
vulgaris $(\mathrm{CV})$ were analyzed. In a second group, based on the results of group one, only hydroponic medium was used given its simplicity and microbial associations were tested with single or combined free cells.

\section{Stem length}

The ANOVA analysis of the first set of experiments showed that the associated microorganism, elapsed time and salinity were the only significant factors for plant growth, despite of the used medium (MS or hydroponic), (Table 1). It is remarkable that as long as $\mathrm{NaCl}$ increased in concentration form 0 to $250 \mathrm{mM}$ the stem length diminished, in any case $A$. brasilense Cd-BIF promoted longer stems in the seedlings. C. vulgaris had the second better results in this measure (Figure 1a). Regarding salinity, two groups are clearly differentiated, Group I: $\mathrm{NaCl}$ concentrations 0,50 and $100 \mathrm{mM}$ with stem lengths average of $22.7 \pm$ $0.6 \mathrm{~mm}$ and Group II: $\mathrm{NaCl}$ concentrations 150, 200 and 250 with stem lengths average of $17.8 \pm 0.6 \mathrm{~mm}$. When considering time as a second factor, it can be seen that as long as time passed the seedlings were less tolerant to salt, as stem lengths were shorter $\sim 15$ and $20 \mathrm{~mm}$ in comparison to the first ten days were stem lengths were in the range of 25 to $26 \mathrm{~mm}$ (Figure 1b). In general, those seedlings growing with any microorganism associated showed longer stems in comparison to the control, where no microbial association was used, which means that salt tolerance is favored by plant microbial associations.

If the average of stem elongation through the three periods of time is considered, $A$. brasilense $\mathrm{Cd}-\mathrm{BIF}$ showed the major elongation in the stems $(21.8 \pm 0.07 \mathrm{~mm})$ in comparison to the other microbial treatments. However, at the end of 30 days period the stems were shorter than those observed at 10 days, and this was true for almost all cases, ex- cept for $A$. brasilense $\mathrm{Cd}$ where the longitudes of the stems $(22.3 \pm 0.12 \mathrm{~mm})$ were significantly larger $(\mathrm{p}<0.05)$ than other treatments after 30 days (Figure 1b).

For the second set of experiments, where combined microorganisms were tested, according to the ANOVA analysis (Table 2) the combination of $A$. brasilense $\mathrm{Cd}$ and C. vulgaris (AWCV) had a better impact on stem growth $(25.3 \pm 0.7 \mathrm{~mm})$ followed by the associated $A$. brasilense $\mathrm{Cd}-\mathrm{BIF}$ and $C$. vulgaris (ABCV) $(23.3 \pm 0.8 \mathrm{~mm})$ (Figure 2a). Longer stems were observed at 20 days in those seedlings associated to $A$. brasilense $\mathrm{Cd}$ and $C$. vulgaris (AWCV) (29.8 $\pm 1.3 \mathrm{~mm}$ ), showing even higher results at $\mathrm{NaCl}$ concentrations below $100 \mathrm{mM}$ (up to $30.6 \pm 1.7 \mathrm{~mm}$ ), but as before, in general the tendency of stems was to decrease in size as long as $\mathrm{NaCl}$ concentration increased; nonetheless, seedlings associated with $\mathrm{ABCV}$ showed longer stems than any other treatment at $250 \mathrm{mM}$ of $\mathrm{NaCl}$ $(25.7 \pm 3.3 \mathrm{mM})$ (Figure 2b).

\section{Root length}

Conversely with stem length, the microbial association had no statistical significant differences $(p<0.05)$ in root length but growing medium (Table 3 ). Those seedlings grown in MS medium averaged longer roots (1.29 \pm $0.03 \mathrm{mM}$ ) in contrast to those seedlings grown in hydroponic medium $(1.13 \pm 0.03 \mathrm{mM})$. Time and salinity also were significant factors for root length; though, salinity effects cannot be grouped in two as before (Figure 3a).

Regarding salinity, those seedlings grown in 50 and $100 \mathrm{mM} \mathrm{NaCl}$ showed the longer roots, $1.3 \pm 0.05$ and $1.4 \pm$ $0.05 \mathrm{~mm}$ respectively, in comparison with the rest of the treatments. In the first 10 days, it can be observed that 50 and $100 \mathrm{mM}$ of $\mathrm{NaCl}$ promoted longer roots and this

Table 1 - Analysis of Variance for Stem Length (mm) for two growing media and simple free cells.

\begin{tabular}{|c|c|c|c|c|c|}
\hline Source & SS & df & MS & F-ratio & p-value \\
\hline \multicolumn{6}{|l|}{ Main effects } \\
\hline $\begin{array}{l}\text { A: Microbial Associa- } \\
\text { tion }\end{array}$ & 919.315 & 3 & 306.438 & 10.69 & 0.0000 \\
\hline B:Time (d) & 1075.01 & 2 & 537.505 & 18.75 & 0.0000 \\
\hline C:Salinity (mM) & 3148.09 & 5 & 629.618 & 21.96 & 0.0000 \\
\hline D:Medium & 39.7511 & 1 & 39.7511 & 1.39 & 0.2396 \\
\hline \multicolumn{6}{|l|}{ Interactions } \\
\hline $\mathrm{AB}$ & 1628.29 & 6 & 271.381 & 9.46 & 0.0000 \\
\hline $\mathrm{AC}$ & 1199.53 & 15 & 79.9689 & 2.79 & 0.0004 \\
\hline $\mathrm{AD}$ & 538.267 & 3 & 179.422 & 6.26 & 0.0004 \\
\hline $\mathrm{BC}$ & 2292.38 & 10 & 229.238 & 7.99 & 0.0000 \\
\hline $\mathrm{BD}$ & 570.949 & 2 & 285.475 & 9.96 & 0.0001 \\
\hline $\mathrm{CD}$ & 35.2102 & 5 & 7.04204 & 0.25 & 0.9419 \\
\hline Residuals & 13562.9 & 473 & 28.6743 & & \\
\hline Total (Corrected) & 25775.8 & 525 & & & \\
\hline
\end{tabular}



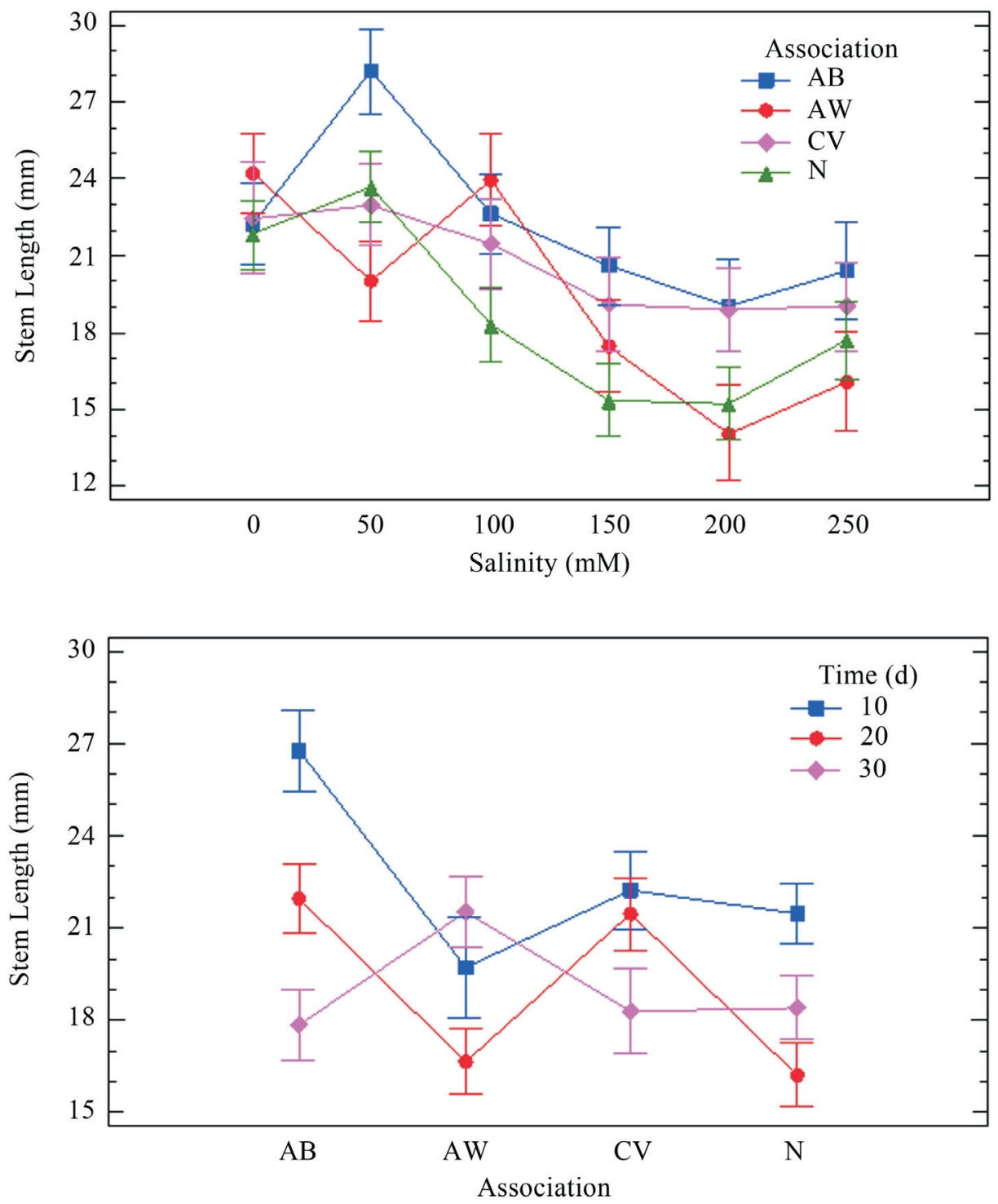

Figure 1 - a) Stem lengths for seedlings in relation to $\mathrm{NaCl}$ concentrations using different microbial associations for MS and hydroponic media. b) Stem lengths for seedlings growing in different microbial associations in three periods of time.

Table 2 - Analysis of Variance for Stem Length ( $\mathrm{mm}$ ) for hydroponic media using simple and combined cells.

\begin{tabular}{|c|c|c|c|c|c|}
\hline Source & SS & $\mathrm{df}$ & MS & F-ratio & $\mathrm{p}$-value \\
\hline \multicolumn{6}{|l|}{ Main effects } \\
\hline $\begin{array}{l}\text { A: Microbial Associa- } \\
\text { tion }\end{array}$ & 1839.61 & 5 & 367.922 & 13.75 & 0.0000 \\
\hline B:Time (d) & 73.1129 & 2 & 36.5565 & 1.37 & 0.2565 \\
\hline C:Salinity (mM) & 1873.94 & 5 & 374.789 & 14.01 & 0.0000 \\
\hline \multicolumn{6}{|l|}{ Interactions } \\
\hline $\mathrm{AB}$ & 1878.47 & 10 & 187.847 & 7.02 & 0.0000 \\
\hline $\mathrm{AC}$ & 2076.13 & 25 & 83.0454 & 3.1 & 0.0000 \\
\hline $\mathrm{BC}$ & 602.975 & 10 & 60.2975 & 2.25 & 0.0147 \\
\hline Residuals & 9419.46 & 352 & 26.7598 & & \\
\hline Total (Corrected) & 18329.9 & 409 & & & \\
\hline
\end{tabular}



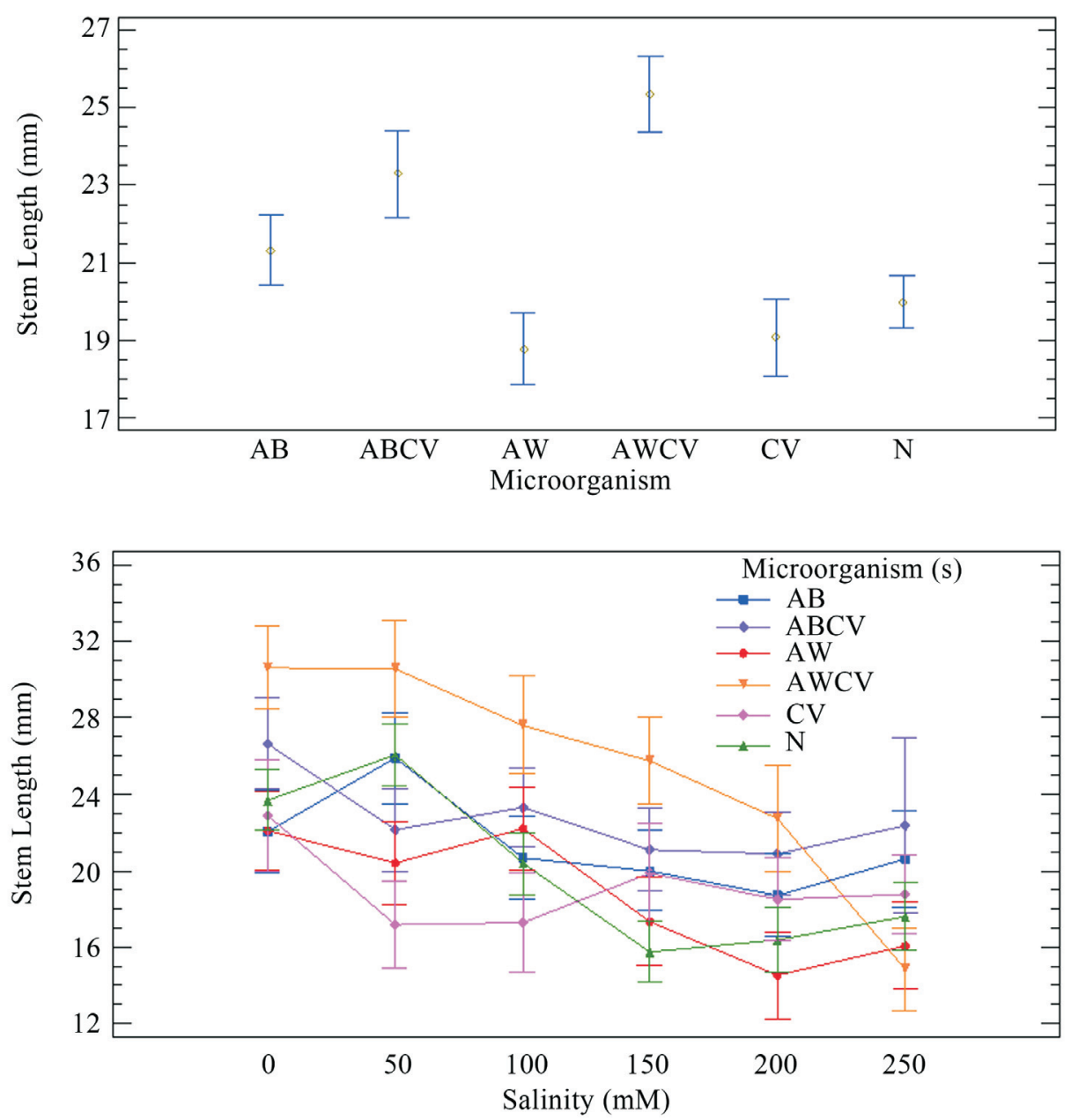

Figure 2 - a) Confidence intervals $(\alpha=0.05)$ for averaged stem lengths for seedlings growing in association with different microorganisms in hydroponic medium. b) Stem lengths for seedlings in relation to $\mathrm{NaCl}$ concentrations using different microbial associations for hydroponic media in the second set of experiments.

Table 3 - Analysis of Variance for Root Length ( $\mathrm{mm}$ ) for two growing media.

\begin{tabular}{lccccc}
\hline Source & SS & df & MS & F-ratio & p-value \\
\hline Main effects & & & & 2.48 & 0.0317 \\
A: Association & 136.578 & 5 & 27.3155 & 0.27 & 0.7633 \\
B:Time (d) & 5.9548 & 2 & 2.9774 & 4.16 & 0.0011 \\
C:Salinity (mM) & 229.184 & 5 & 45.8369 & & 0.7 \\
Interactions & & & & 1.93 & 0.0053 \\
AB & 737.614 & 10 & 73.7614 & 3.75 & 0.0001 \\
AC & 531.986 & 25 & 21.2795 & & \\
BC & 412.965 & 10 & 41.2965 & 11.0163 & \\
Residuals & 3888.76 & 353 & & & \\
Total (Corrected) & 5785.52 & 410 & & & \\
\end{tabular}

growth pattern was consistent for the next 10 days but showing shorter roots and this is true until 30 days (Figure $3 b)$.
In the second set of experiments where hydroponic medium was the only one used, time had no statistical effect on root length, but associated microorganisms and salinity (Figure 4). According to the analysis of variance, those 

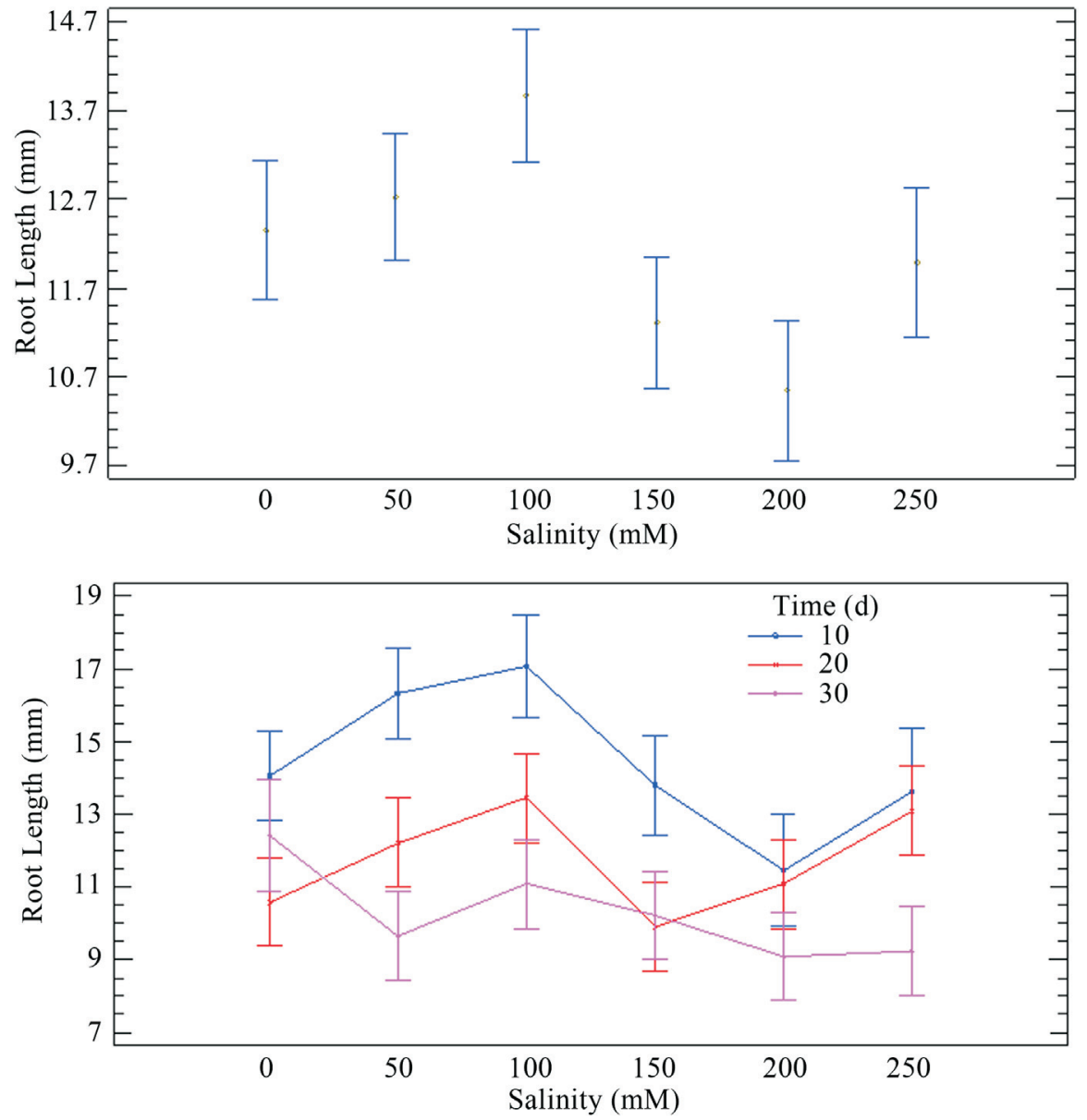

Figure 3 - a) Confidence intervals $(\alpha=0.05)$ for averaged stem lengths for seedlings growing at different $\mathrm{NaCl}$ concentrations in MS and hydroponic media. b) Effect of salinity concentration on root length through the time for MS and hydroponic media.

seedlings associated with $C$. vulgaris where different to control having longer roots $(12 \pm 0.4 \mathrm{~mm})$ (Figure 4a). Even when the effects of $\mathrm{NaCl}$ concentration are not differentiated in groups as easily as with stems, in roots is noteworthy the influence of $100 \mathrm{mM}$ of $\mathrm{NaCl}$ with longer roots $(12.6 \pm 0.4 \mathrm{~mm})$.

Concomitantly, AW had a marked effect on root elongation after 30 days $(13.2 \pm 0.7 \mathrm{~mm})$, similar to that observed for $\mathrm{CV}$ at the end of the first 10 days $(13.2 \pm 0.8 \mathrm{~mm})$ with control showing the shorter roots after 20 and 30 days of treatment (Figure $4 b$ ).

\section{Discussion}

Hydroponic culture of plants with sea water or even salted water and the use of biofertilizers is a promising technology in order to mitigate the salinity effect on food crops. In the present work we planned to analyze the effects of Azospirillum brasilense Cd wild type, A. brasilense Cd-BIF able to over accumulate the osmoprotectant trehalose and Chlorella vulgaris in the growth of tomato seedlings using two different culture media and in microbial association.

According to the observed results, Azospirillum basilense Cd-BIF followed by Chlorella vulgaris showed the better influence in seedlings promoting longer stems, with good results even at $250 \mathrm{mM}$ of $\mathrm{NaCl}$. Given that microbial associations showed in general better results for stem and roots elongation in tomato seedlings, this could imply that these plants could be irrigated with sea water at least partially when associated to any of this microorganisms. Seemingly, if the concentration of $\mathrm{NaCl}$ is increased for those seedlings growing in hydroponic medium, the effect of $A$. brasilense Cd-BIF will be better; meanwhile the triple association of $A$. brasilense $\mathrm{Cd}$, C. vulgaris plus seedlings appears to be sensitive to $\mathrm{NaCl}$ increments. These results are in agreement with those works reported previously about Azospirillum brasilense growing up to $200 \mathrm{mM}$ of $\mathrm{NaCl}$, where no drop in bacterial growth rate was observed, but when $300 \mathrm{mM}$ of $\mathrm{NaCl}$ was used, the growth rate diminished in 66\% (Rivarola et al., 1998). In our results, $A$. brasilense $\mathrm{Cd}$ showed almost the same growing behavior, 

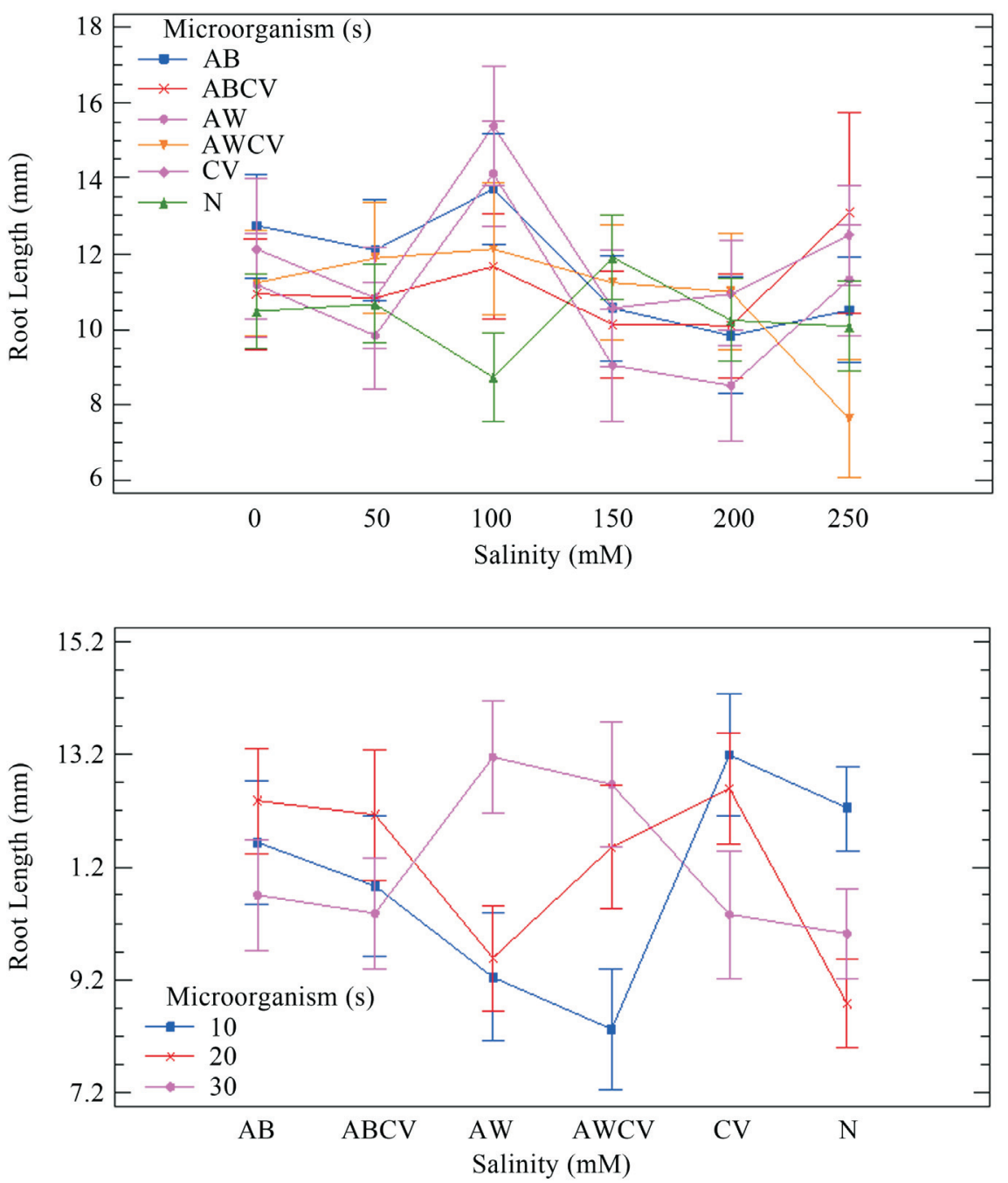

Figure 4 - a) Root lengths for seedlings in relation to $\mathrm{NaCl}$ concentrations using different microbial associations for hydroponic media in the second set of experiments. b) Root lengths for seedlings growing in different microbial associations for three periods of time in hydroponic media in the second set of experiments.

however we assume that $A$. brasilense Cd-BIF could grow with no problems even up to $300 \mathrm{mM}$.

In previous works with plants of Zea mayz under osmotic stress, Rodríguez-Salazar et al. (2009) observed an increased biomass, namely thicker roots, of those plants grown in association with $A$. brasilense Cd-BIF. Other works with maize and wheat report an osmoadaptative phenomena for those plant cells associated with $A$. brasilense (El-Baky et al., 2008)(2, 16). Some other examples in wheat and barley suggest that the association plantmicroorganism are beneficial for plant's salt tolerance due to an increase in its growing capacity (Caballero-Mellado, 2006; Zawoznik et al., 2011).

On the other hand, Hiremath and Mathad et al. (2010) demonstrated that Chlorella vulgaris was positively stimulated by up to $200 \mathrm{mM}$ of $\mathrm{NaCl}$ for chlorophyll and proline production, but when salinity concentration was increased up to $300 \mathrm{mM}$ a reduction on chlorophyll was observed.
Díaz et al. (1999)) reported that proline accumulates in plants in response to increased environmental salinity. These supports the evidence showed here regarding $C$. vulgaris and its effect on plant tolerance as mentioned above, where $C$. vulgaris had the second marked effect on salt tolerance over the seedlings of tomato.

In general, stems and roots lengths decreased with time, despite of the applied treatment and this could be a cause of the prolonged immersion time of the seedlings in the nutritive solutions, thus is advisable to add some kind of support for the plant. This is why for a future work we are planning to evaluate the effect of these microbial species in seedlings growing in alginate beads supports. As our results suggests, the use of $A$. brasilense $\mathrm{Cd}-\mathrm{BIF}$ and $C$. vulgaris is a viable approach to increase the salt tolerance in plants and their biomass and the possible use of sea water to irrigate horticultural plants. 


\section{Acknowledgement}

The main authors wish to thank the Doctoral fellowship 162578 by CONACYT to Daniel Cortés and Abril Gómez, respectively. We express our gratitude to Virginia Berenice Suarez for her English correction proof.

\section{Abbreviations}

AW, Azospirillum brasilense Cd (wild type)

$\mathrm{AB}$, Azospirillum brasilense $\mathrm{Cd}$ with plasmid pBBR1M:BIF

PGPB, Plant Growth Promoting Bacteria

$\mathrm{CV}$, Chlorella vulgaris

\section{References}

Abd El Baky HH, Hussein MM, El-Baroty GS (2008) Algal extracts improve antioxidant defense abilities and salt tolerance of wheat plant irrigated with sea water. African $J$ of Biochem Res 2:151-164.

Abd El-Samad Hamdia M, Shaddad MAK, Doaa MM (2004) Mechanisms of salt tolerance and interactive effects of Azospirillum brasilense inoculation on maize cultivars grown under salt stress conditions. Plant Growth Regulation 44:165-174.

Bacilio M, Rodriguez H, Moreno M, Hernandez JP, Bashan Y (2004) Mitigation of salt stress in wheat seedlings by a gfp-tagged Azospirillum lipoferum. Biol Fertil Soils 40:188-193.

Bischoff HW, Bold HC (1963) IV. Some soil algae from Enchanted Rock and related algal species. In: Andersen RA (ed) Algal Culturing Techniques. Elsevier Academic Press, London, pp 1-95.

Caballero-Mellado J (2006) Microbiología agrícola e interacciones microbianas con plantas. Rev Latinoam Microb 48:154-161.

Canto MJC, Medina PS, Morales AD (2004) Efecto de la inoculación con Azospirillum spp. en plantas de chile habanero (Capsicum chinense Jacquin). Tropical and subtropical Agroecosystems 4:21-27.

De-Bashan LE, Hernandez JP, Morey T, Bashan Y (2004) Microalgae growth-promoting bacteria as "helpers" for microalgae: a novel approach for removing ammonium and phosphorus from municipal wastewater. Water Res 38:466-474.

Díaz P, Borsani O, Monza J (1999) Acumulación de prolina en plantas en respuesta al estrés osmótico. Agrociencia 3:1-10.

Givaudan A, Bally R (1991) Similarities between large plasmids of Azospirillum lipoferum. FEMS Microbiol Lett 78:245-251.

Hartmann A, Mahavir S, Klingmulle W (1983) Isolation and characterization of Azospirillum mutants excreting high amounts of indoleacetic acid. Can J Microbiol 29:916-923.

Hiremath S, Mathad P (2010) Impact of salinity on the physiological and biochemical traits of Chlorella vulgaris Beijerinck. J Algal Biomass Utln 1:51-59.

Jensen MM, Malter A (1995) Protected Agriculture: A Global Review. World Bank Technical Paper \#253. The World Bank, Washington, DC, $157 \mathrm{pp}$.

Mazur A, Konop A, Synak R (2001) Indole-3-acetic acid in the culture medium of two axenic green microalgae. J Appl Phycol 13:35-42
Meloni D, Gulotta M, Martínez C (2008) Salinity tolerance in Schinopsis quebracho colorado: Seed germination, growth, ion relations and metabolic responses. J Arid Environm 72:1785-1792.

Murashige T, Skoog F (1962) A revised medium for rapid growth and bioassays with tobacco tissue culture. Physiol Plant 15:473-479.

Nagarajan T, Vanderleyden J, Kumar TK (2007) Identification of salt stress inducible genes that control cell envelope related functions in Azospirillum brasilense Sp7. Mol Genet Genomics 278:43-51

Nasr, SMH, Parsakhoo A, Skandari S, Gojani HJ, Savad-Koohi SK (2012) Investigation of salinity tolerance in Dodonaea viscosa L. J Appl Biol Sci 6:31-36.

Perrig D, Boiero L, Masciarelli O, Penna C, Cassán F, Luna V (2007) Plant growth promoting compounds produced by two agronomically important strains of Azospirillum brasilense and their implications for inoculant formulation. Appl Microb Biotech 75:1143-1150.

Porta C, López-Acevedo M, Roquero C (1999) Edafología para la Agricultura y el Medio Ambiente. Mundi-Prensa, Madrid.

Potters G, Pasternak TP, Guisez Y, Palme JP, Jansen MAK (2008) Stress-induced morphogenic responses: growing out of trouble? Trends in Plant Sci 12:98-105.

Ríos-Gómez R, Salas-García CE, Monroy-Ata A, Solano E (2010) Salinity effect on Prosopis laevigata seedlings. Terra Latinoamericana 28:99-107.

Rivarola V, Castro S, Mori G, Jofré E, Fabra A, Garnica R, Balegno H (1998) Response of Azospirillum brasilense Cd to sodium chloride stress. Antonie van Leeuwenhoek 73:255-261.

Rodríguez-Salazar SJ, Suárez R, Caballero-Mellado J, Iturriaga G (2009) Trehalose accumulation in Azospirillum improves drought tolerance and biomass in maize plants. FEMS Microb Lett 296:52-59.

Stirk WA, Ordog V, Van Staden J, Jager K (2002) Cytokinin-and auxin-like activity in cyanophyta and microalgae. J Appl Phycol 14:215-221.

Strzelczyk E, Kamper M, Li C (1994) Cytocinin-like-substances and ethylene production by Azospirillum in media with different carbon sources. Microbiol Res 149:55-60.

Tobe K, Li X, Omasa K (2000) Seed germination and radicle growth of a halophyte, Kalidium capsicum (Chenopodiaceae). Ann Bot 85:391-396.

Umali-Garcia M, Hubbell DH, Gaskins MH, Dazzo FB (1980) Association of Azospirillum with grass roots. Appl Environ Microbiol 39:219-26.

Velarde M, Felker P, Degano C (2003) Evaluation of Argentine and Peruvian Prosopis germplasm for growth at seawater salinities. J Arid Environ 55:515-531.

Zawoznik MS, Ameneiros M, Benavides MP, Vázquez S, Groppa MD (2011) Response to saline stress and aquaporin expression in Azospirillum-inoculated barley seedlings. Appl Microbiol Biotechnol 90:1389-1397.

Zribi L, Fatma G, Fatma R, Salwa R, Hassan N, Nejib RM (2009) Application of chlorophyll fluorescence for the diagnosis of salt stress in tomato (Solanum lycopersicum, variety Rio Grande). Sci Hort 120:367-372.

All the content of the journal, except where otherwise noted, is licensed under a Creative Commons License CC BY-NC. 